\title{
Frontosubthalamic Circuits for Control of Action and Cognition
}

\author{
Adam R. Aron, ${ }^{1}$ Damian M. Herz, ${ }^{2}$ Peter Brown, ${ }^{2}$ Birte U. Forstmann, ${ }^{3}$ and Kareem Zaghloul ${ }^{4}$ \\ ${ }^{1}$ Department of Psychology, University of California San Diego, San Diego, California 92093-0109, ${ }^{2}$ Medical Research Council Brain Network Dynamics \\ Unit, and Nuffield Department of Clinical Neurosciences, University of Oxford, Oxford OX1 3TH, United Kingdom, ${ }^{3}$ Amsterdam Brain and Cognition \\ Center, University of Amsterdam, Psychology, Roetersstraat 15, Amsterdam 1018, The Netherlands, and ${ }^{4}$ National Institute of Neurological Disorders and \\ Stroke, National Institutes of Health, Baltimore, Maryland 20892
}

The subthalamic nucleus (STN) of the basal ganglia appears to have a potent role in action and cognition. Anatomical and imaging studies show that different frontal cortical areas directly project to the STN via so-called hyperdirect pathways. This review reports some of the latest findings about such circuits, including simultaneous recordings from cortex and the STN in humans, single-unit recordings in humans, high-resolution fMRI, and neurocomputational modeling. We argue that a major function of the STN is to broadly pause behavior and cognition when stop signals, conflict signals, or surprise signals occur, and that the fronto-STN circuits for doing this, at least for stopping and conflict, are dissociable anatomically and in terms of their spectral reactivity. We also highlight recent evidence for synchronization of oscillations between prefrontal cortex and the STN, which may provide a preferential "window in time" for single neuron communication via long-range connections.

Key words: basal ganglia; conflict; oscillations; response inhibition; stopping; surprise

\section{Introduction}

There is burgeoning interest in the subthalamic nucleus (STN) of the basal ganglia. This is driven by a confluence of interests in neurosurgery, neurology, computational modeling, and cognitive neuroscience. A major driver of interest is that research on the STN takes advantage of one of the only regular opportunities to acquire electrophysiological signals from deep within the human brain (i.e., via the implantation of deep brain stimulation [DBS], electrodes in patients with Parkinson's disease). DBS is thought to override or disrupt pathological oscillations, and "free up" the basal ganglia and its associated cortical circuits to better process information (Grill et al., 2004; Wilson et al., 2011). Yet DBS comes with side effects, for example, on speech and cognition (Hershey et al., 2004; Parsons et al., 2006), and there is much interest in optimizing it through better targeting and technical designs (Beudel and Brown, 2016; Kühn and Volkmann, 2016). A better understanding of the STN, its subregions, and its associated circuits (including prefrontal connections) could thus be clinically relevant. Going hand-in-hand with this is the question

\footnotetext{
Received July 22, 2016; revised Aug. 12, 2016; accepted Aug. 14, 2016.

A.R.A. was supported by National Institutes of Health DA DA026452 and James S. McDonnell Grant 220020375. D.M.H. was supported by European Union's Horizon 2020 research and innovation program under the Marie Sklodowska-Curie Grant Agreement 655605. P.B. was supported by Medical Research Council of Great Britain MC_UU_12024/1. B.U.F. was supported by the European Research Council and Netherlands Organization for Scientific Research. We thank Nader Pouratian for discussion, Navarre Guiterrez-Read for assistance with the figure, and Johanna Wagner and Eleonora Bartoli for comments on the manuscript.

The authors declare no competing financial interests.

Correspondence should be addressed to Dr. Adam R. Aron, Department of Psychology, University of California San Diego, 9500 Gilman Drive, La Jolla, CA 92093-0109. E-mail: adamaron@ucsd.edu.

DOI:10.1523/JNEUROSCI.2348-16.2016

Copyright $\odot 2016$ the authors $\quad 0270-6474 / 16 / 3611489-07 \$ 15.00 / 0$
}

of what computations does the STN and its circuits do. Much recent research has focused on the idea that the STN plays a role in decision-making. Specifically, it has been proposed that the STN pauses responding by raising the decision threshold, and that it does this by suppressing basal ganglia output (Bogacz and Gurney, 2007; Wiecki and Frank, 2013; Zavala et al., 2015a). Here we put forward the hypothesis that this computational pause function is implemented by different (dissociable) cortico-STN circuits for different behavioral contexts. We mainly focus on the behavioral functions of stopping and conflict in the response domain. We end by considering how an STN-mediated pause might also affect cognition.

\section{Stopping}

Stopping is a neurocognitive process that countermands an initiated response tendency. It is typically studied in the laboratory with stop signal and Go/NoGo tasks (Verbruggen and Logan, 2008; Chambers et al., 2009; Chikazoe, 2010; Schall and Godlove, 2012; Bari and Robbins, 2013). On each trial, the subject prepares to Go, and sometimes has to try to stop the incipient response when a stop signal occurs. The go process (initiating a response) activates premotor cortex and downstream striatum, pallidum, thalamus, and M1 (consistent with the direct pathway of the basal ganglia) (Aron and Poldrack, 2006; Schmidt et al., 2013). The stop process activates (and requires the integrity of) specific frontal regions, such as the right inferior frontal cortex (IFC) and the presupplementary motor area (pre-SMA) (for review, see Wiecki and Frank, 2013; Aron et al., 2014; Jahanshahi et al., 2015); it also activates the STN (see below) and the globus pallidus pars interna (GPi) (Aron and Poldrack, 2006; Li et al., 2008; Schmidt et al., 2013; Watanabe et al., 2015) and striatum (Aron and Poldrack, 
2006; Zandbelt and Vink, 2010). Many studies now attest to the STN's role in outright action stopping, including human fMRI (Aron and Poldrack, 2006; Li et al., 2008), human lesion (Obeso et al., 2014), human STN local field potential (LFP) (Kühn et al., 2004; Alegre et al., 2012; Ray et al., 2012; Benis et al., 2014), rat lesion (Eagle et al., 2007), and singleunit studies in humans (Bastin et al., 2014), monkeys (Isoda and Hikosaka, 2008), and rats (Schmidt et al., 2013). While individual approaches have their weaknesses (e.g., 3T fMRI may not be optimal for definitive localization (de Hollander et al., 2015), LFP changes in the STN likely reflect basal-ganglia wide rather than STN-specific signatures (Leventhal et al., 2012) and the rodent lesion study apparently affected going more than stopping), taken together, a strong case is made that the STN is implicated in stopping. Ultimately, however, confirmation requires causal approaches, such as optogenetics.

As we saw, two prefrontal areas critical for stopping are the right IFC and the preSMA. While their relative functional roles are still unclear (Zandbelt et al., 2013; Aron et al., 2014; Herz et al., 2014; Rae et al., 2015; Xu et al., 2016), we suppose that one or both is recruited by the stop signal to trigger the STN via a hyperdirect pathway. The original idea of the hyperdirect pathway was that it has a broad suppressive effect on basal ganglia output (Mink, 1996; Gillies and Willshaw, 1998; Nambu et al., 2002). This was based on tracing studies in the monkey (for review, see Parent and Hazrati, 1995), yet the evidence is weak. Notwithstanding, there is now considerable evidence that stopping action does have broad behavioral/physiological suppressive effects. This was established by studies that use transcranial magnetic stimulation and concurrent motor-evoked potentials: a corticospinal excitability measurement method. Specifically, stopping speech reduces corticospinal excitability of the hand (Cai et al., 2012; Wessel et al., 2016b), stopping the eyes reduces corticospinal excitability of the hand (Wessel et al., 2013a); and stopping the hand reduces corticospinal excitability of the leg (Badry et al., 2009; Greenhouse et al., 2012; Majid et al., 2012). Moreover, stopping one movement leads to large delays in continuing with another (Coxon et al., 2007; MacDonald et al., 2014). Interestingly, the level of global suppression (measured from the hand when stopping speech) has been linked to a "stopping signature" in the STN, viz. increased power of oscillations in the LFP (Wessel et al., 2016b). Notably, the oscillations increased their power in the beta band (13-30 Hz), consistent with several other STN LFP recording studies during stop trials (Kühn et al., 2004; Ray et al., 2012; Bastin et al., 2014; Benis et al., 2014). Moreover, increases in beta band power have been reported for right IFC (Swann et al., 2009, 2012; Wessel et al., 2013b) and pre-SMA (Swann et al., 2012). These increases of beta band power in the STN and in prefrontal regions known to be critical for stopping raise the intriguing possibility that these signatures are linked, and that a prefrontal-STN stopping system operates via "communication" in the beta frequency band (cf. Fries, 2005) (Fig. 1A). The evi-

\section{B Conflict}

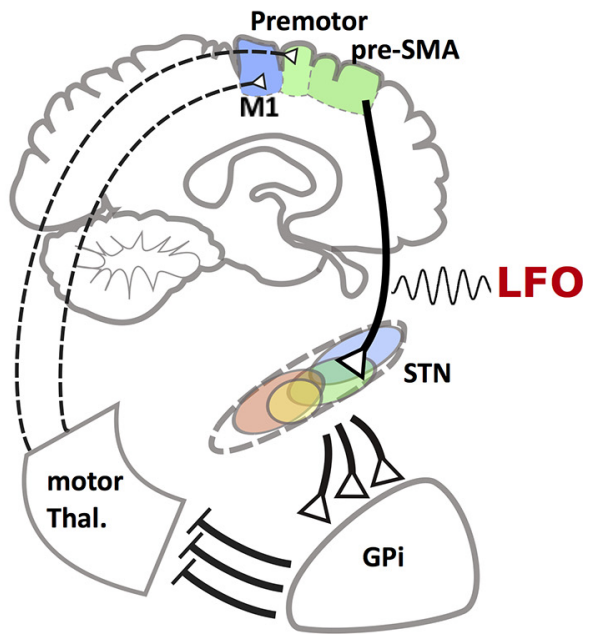

Premotor
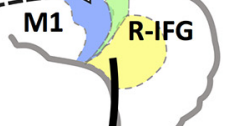

$\mu$

GPi

STN

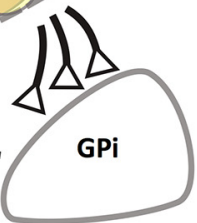

topping is initiated via right inferior frontal gyrus (R-IFG) (possibly in concert with pre-SMA), which projects to the central part of the STN. The STN topography in the figure is based on monkey tracing, with areas color coded by cortical inputs (orange represents ventromedial nent. $\boldsymbol{B}$, Conflict operates in an analogous way, except it appears to be generated by dmPFC (perhaps pre-SMA), and this projects territory. Power increases now occur for low-frequency oscillations, LFOs, in the $2-8 \mathrm{~Hz}$ band.

dence for this idea is clearer for tasks that elicit conflict, to which we now turn.

\section{Conflict}

Parallel to the research on stopping is research on the topic of response conflict and decision conflict. It was proposed that, when conflict is detected, the STN implements a "hold your horses" pause (Frank, 2006). This can be understood as follows (and see Zavala et al., 2015a). In the standard basal ganglia model, response initiation requires removing the GPi's inhibition of thalamus. However, in situations involving conflict, two or more premotor responses are simultaneously activated. This conflict signal is detected by dorsomedial frontal cortex (putatively the pre-SMA) (Taylor et al., 2007; Wiecki and Frank, 2013), which then recruits the STN via a hyperdirect pathway. The recruitment of the STN increases GPi's (supposedly broad) inhibition of thalamus. To overcome this, the movement-related corticostriatal input needs to be stronger to silence the GPi. The result is that a higher "threshold" of cortical evidence is needed to drive a response. Over time, the premotor representation associated with the correct response will rise, whereas those associated with other response representations will not. Eventually, the correct response will be selected, but with longer reaction time relative to low-conflict trials.

Several studies are now consistent with an STN role during conflict. Oscillatory power increases are seen for high conflict trials in the STN for Stroop, Eriksen Flanker, and decision tasks (Brittain et al., 2012; Cavanagh et al., 2011; Fumagalli et al., 2011; Zavala et al., 2013, 2014). The power increase is in the $2-8 \mathrm{~Hz}$ range, which we hereafter refer to as low-frequency oscillations (LFOs). There are also conflict-related LFO increases in scalp EEG sites corresponding to dorsomedial frontal cortex (Cohen and Cavanagh, 2011; Cavanagh et al., 2012). This picture from LFP studies fits with a substantial imaging literature showing that conflict activates dorsomedial frontal cortex, including parts of 
the dorsal cingulate and also, notably, the pre-SMA (see metaanalysis) (Ridderinkhof et al., 2004). The observations that LFO increases in the dorsomedial prefrontal cortex (dmPFC, perhaps pre-SMA) and the STN, and that these are connected via white matter (see below), raises the possibility that a prefrontal-STN conflict system operates via intersite coherence in the LFO (as opposed to the beta frequency band for stopping) (Fig. 1B). Indeed, coherence for the LFO between the scalp EEG and the STN LFP has been shown for a perceptual decision-making task involving conflicting sensory information, and it was also suggested that the former causes the latter (Zavala et al., 2014).

While the empirical evidence reviewed above has pointed to the putative dorsomedial frontal-STN system, relevant neurocomputational models have also been developed. These make concrete predictions about the STN's role in elevating decision thresholds so that more evidence is accumulated before responding (Bogacz and Gurney, 2007; Wiecki and Frank, 2013). Consistent with these models, two studies combining computational modeling of decision-making parameters with fMRI found that trial-by-trial variations in STN activity were positively correlated with variations in decision thresholds (Mansfield et al., 2011; Frank et al., 2015). In a recent study, Herz et al. (2016) recorded STN LFPs to further test the involvement of the STN in modulating decision thresholds. They found that LFO preceding the response predicted the adjustment of decision threshold on each trial during two perceptual decision-making tasks. Importantly, the exact relationship depended on the level of cautiousness in the respective task, so that increased LFO predicted increased thresholds only in the task inducing stronger response caution, although it predicted decreased thresholds in the simpler task. A possible neural mechanism underlying this context-specific modulation is the dynamic reconfiguration of distinct neural networks connecting the STN and cortical areas (Fogelson et al., 2006). In particular, as noted above, the dmPFC has been suggested to increase its influence over STN during conflict and increased task difficulty (Ridderinkhof et al., 2011; Wiecki and Frank, 2013). Consistent with this, the extent to which LFO in $\mathrm{dmPFC}$ and STN fall in to register is related to elevated decision thresholds and reduced error rates (Herz et al., 2016). The functional role of dmPFC-STN connectivity in setting decision thresholds is further corroborated by a study which found a correlation between decision thresholds and the interaction between STN BOLD activity and LFO in dmPFC EEG (Frank et al., 2015). Of note, this relationship was also specific to trials with high conflict.

Thus, these studies suggest that STN activity determines adjustments of decision thresholds depending on the "effectiveness" of cortical inputs from the PFC. Below we review the singleunit evidence during conflict tasks and explain how optimal alignment of the peaks and troughs in LFO between dmPFC and STN may provide a preferential "window in time" for single neuron communication (Zavala et al., 2015b; Herz et al., 2016). In this schema, adjustments of decision thresholds may then be instantiated through STN-mediated down modulation of movement facilitating corticobasal ganglia feedback loops when cautiousness is warranted, leading to decreased baseline activity and gain of cortical neurons integrating sensory evidence (Hanks et al., 2014; Thura and Cisek, 2016).

\section{Imaging and anatomy}

As we saw, research on stopping points to the critical importance of the right IFC and pre-SMA, and research on conflict points to $\mathrm{dmPFC}$, including the pre-SMA. Because stopping needs to be very quick, and perhaps broad in its effects, a hyperdirect cortical-STN system may be recruited; and the same rationale may apply to conflict. Several lines of evidence support the hyperdirect pathway idea

First, studies that stimulate cortex and record from the STN in a rodent reveal a short latency $(<10 \mathrm{~ms})$ glutamatergic input (Magill et al., 2004; for review, see Nambu et al., 2002). Second, early tracing studies in monkeys emphasized direct connections to the STN from primary motor, and premotor cortex (including the pre-SMA) (Nambu et al., 1997; Inase et al., 1999). Recently, a large study injected anterograde tracers into multiple sites in macaque primary motor and prefrontal cortex (PFC), including ventromedial prefrontal, orbitofrontal, anterior cingulate, and dorsal prefrontal cortices (Haynes and Haber, 2013). This study revealed a topographically organized hyperdirect pathway: with primary motor cortex projecting to dorsal STN, premotor cortex to a slightly more ventral area, dorsolateral PFC to an even more ventral area and on toward the "limbic" STN tip. This elegant study has significant implications for the current view on the topographic organization of the STN: it suggests that, rather than a simple tripartite motor/associative/limbic organization (Temel et al., 2005), the STN instead represents an overlap over multiple domains based on different cortical inputs (Alkemade, 2013; Alkemade et al., 2015). Third, human studies using diffusion tensor imaging have also provided evidence for connections between PFC and STN. It was shown that both pre-SMA and right IFC project to a midbrain area consistent with the STN (Aron et al., 2007), and several studies have ratified this and showed that white matter variability in these connections relates to stopping speed (Coxon et al., 2012; Forstmann et al., 2012; King et al., 2012; Rae et al., 2015; Xu et al., 2016). Future studies, including ultra-high resolution 7 tesla (or higher) structural MRI and fMRI with submillimeter resolution will provide the opportunity to investigate more fine-grained topological differences within the STN in humans (see, e.g., Keuken and Forstmann, 2015). This could be used to test one implication of our theory, which is that, consistent with the monkey tract tracing results (Haynes and Haber, 2013), stopping (putatively originating in lateral PFC) should activate a more ventral sector of STN than conflict (putatively originating in pre-SMA).

Although there is substantial anatomical and imaging evidence for hyperdirect pathways, it is notable that there is still scant functional evidence that these pathways implement stopping or conflict. Perhaps the only specific evidence to date is a study in nonhuman primates, which showed that the requirement to override a planned saccade produced single-unit STN increases $\sim 10 \mathrm{~ms}$ after single-unit increases in the pre-SMA (Isoda and Hikosaka, 2008). This small timing difference is consistent with a hyperdirect pathway without intervening synapses.

\section{Single-unit studies}

Although changes in oscillatory power relate to the decision processes in cortex and STN, it is the interaction between oscillations and the firing rate dynamics of the basal ganglia that are ultimately responsible for how an action unfolds. We now turn to single-unit STN recording studies of stopping and conflict.

A recent study of stopping in the rat recorded single-unit activity from multiple basal ganglia nuclei, including STN and $\mathrm{SNr}$ (rodent GPi) (Schmidt et al., 2013). In the SNr, the firing rate decreased following the Go signal, consistent with the classic direct pathway view of a striatal GABAergic influence. In the STN, firing increased quickly after the stop signal on both successful and failed stop trials, consistent with the idea that it was being 
recruited to stop the action. Strikingly, on successful stop trials, the firing rate in the $\mathrm{SNr}$ increased $\sim 16 \mathrm{~ms}$ after the STN, consistent with the idea of countermanding the initiated motor command, whereas on failed stop trials this did not happen. The suggestion that STN spiking activity may be involved in stopping has been supported in both primates and humans. In a recent study examining human STN neuronal responses during a stopping task, one population activated during successful inhibitory control, implicating at least some STN neurons in stopping (Bastin et al., 2014). Similarly, in a primate study, a population of neurons exhibited increased phasic spiking activity when switches were made from automatic to volitionally controlled saccades (Isoda and Hikosaka, 2008). These data suggest that STN spiking activity is involved in inhibiting motor responses, but future research is required to establish whether the STN only implements a pause, or can also stop responses outright.

For conflict, several studies have shown that STN spiking activity is modulated when subjects are asked to prevent or delay responses or when they make decisions during high levels of doubt (Zaghloul et al., 2012; Burbaud et al., 2013; Zavala et al., 2015b). In these cases, spiking activity within the STN increases when the behavioral demands require a decision among competing alternatives, which although not identical to the demands required during stopping, nevertheless involves halting a motor signal until enough information or evidence has been acquired to properly proceed. Regardless, whether these decisions involve choices between learned associations (Zaghloul et al., 2012) or simple sensorimotor decisions involving visual conflict (Zavala et al., 2015b), STN spiking activity increased in the presence of conflict. These increases are consistent with the idea that STN spiking activity exerts a suppressive effect on motor signals, and in the context of decisions, would play a role in effectively adjusting the threshold for activating a specific motor command.

These single-unit results raise some puzzles for the classic model of the basal ganglia. This classic model posits that the striatum inhibits firing rate in GPi via the excitatory direct pathway (Go), and that striatum increases the firing rate in the GPi via the GPe (i.e., via the inhibitory indirect pathway, Stop) (Albin et al., 1989; DeLong, 1990)—and also supported by some optogenetic studies, (e.g., Kravitz et al., 2012). Within this classic framework, activity in the STN has been hypothesized to play a role in stopping motor responses via the inhibitory indirect pathway (Bogacz and Gurney, 2007; Isoda and Hikosaka, 2008). Although the traditional model assigns STN firing an antikinetic role over thalamocortical drive, the functional architecture is likely more complex. First, it is not clear whether it is solely changes in firing rate that are important for STN activity or whether it is instead changes in the temporal patterns of activity (Nambu et al., 2015). Second, both direct and indirect pathways are recruited as part of movement (Cui et al., 2013) and different neuronal subpopulations within the STN show opposite patterns of spiking: some populations increase while others decrease with movement (Bastin et al., 2014; Nambu et al., 2015; Zavala et al., 2015b). These contrary responses in STN firing, also seen in songbirds (Goldberg et al., 2013), suggests that neuronal populations within the STN are heterogeneous in their response to movement. One possible explanation, which is not straightforward to reconcile with global suppression, is that motor circuits within the basal ganglia are organized in multiple parallel loops with a center-surround architecture (Mink, 1996; Nambu et al., 2002). In this scheme, decreases in STN activity are specific to circuits involved in a desired motor movement, facilitating a command to move a single finger, for instance, whereas undesired movements, such as those of the other fingers, would be suppressed by increases in the corresponding circuits responsible for those actions within the STN. Better understanding STN spiking, and directly testing, for example, the center-surround idea, will entail more nonhuman animal research, which is better placed to address these questions. Moreover, as the basal ganglia are increasingly implicated in other aspects of human cognition (Weintraub and Zaghloul, 2013), it also remains unclear whether and how this complexity extends to nonmotor processes that may be mediated through parallel associative and limbic loops (Haber, 2003; McHaffie et al., 2005). Given this complexity, how STN firing activity is involved in stopping and conflict, and whether this is mediated through specific interactions with the indirect pathway or through broad suppressive effects in response to cortical signals relayed via the hyperdirect pathway are an active area of investigation.

Thus, conflict induces both firing rate and oscillatory changes in the STN. How are these signatures linked? Recent evidence from other tasks and modeling suggest that oscillations in the LFP modulate firing rates, and that this is a general mechanism of neural computation that also underlies long-range connectivity (Fries, 2005; Sejnowski and Paulsen, 2006; Rutishauser et al., 2010; Buzsáki et al., 2012; Lisman and Jensen, 2013). Indeed, studies of conflict have shown that single-unit activity within the STN exhibits preferential firing during the peaks of theta and beta oscillations in the presence of conflict (Zavala et al., 2015b). As we saw, there is some evidence from conflict studies that cortex and the STN communicate through frequency-specific oscillations. In this scheme, the medial PFC and right IFC may therefore influence the timing of responses during action selection through synchronized oscillations with the basal ganglia that affect STN spiking activity. Addressing how and whether this occurs is important in ascribing functional significance to the putative hyperdirect pathway between these regions, and also of wider interest for better understanding long-range communication in the human brain.

\section{How the STN may impact cognition}

The STN "pause" function may be recruited by other behavioral requirements than outright stopping to a stop signal and slowing when conflict is detected. One case is that the STN is also apparently engaged by surprising perceptual events. In one paradigm, subjects got ready to respond to an imperative stimulus, but this was preceded by a tone: mostly it was standard, but occasionally it was surprising. Surprise activated the cortical stopping system (Wessel and Aron, 2013), activated the STN (Wessel et al., 2016a), and produced the same transcranial magnetic stimulation signatures of global motor suppression as outright stopping (Wessel and Aron, 2013).

If an STN-mediated stopping system has a broad effect on the skeletomotor system, it might also have an effect on cognition (at least perhaps those aspects of cognition that relate to the motor system, such as verbal and visuomotor working memory $[\mathrm{WM}])$. This was tested by embedding surprising events within a WM paradigm. On each trial, the human subject encoded a letter string into WM, then held this across a delay, then a standard or surprising tone occurred, and soon after that the subject's WM was probed. Surprising events reduced WM accuracy, activated the cortical stopping system, and activated the STN: the more so, the greater the WM decrement (Wessel et al., 2016a). It was argued that verbal WM (at least) is maintained by "looping" thalamocortical drive, and STN activation by the surprising event pauses this, which dec- 
rements WM. Thus, the STN may induce pauses, not just in motor output but also in cognition.

\section{Conclusion}

In conclusion, we have focused on how the STN is engaged by stopping, conflict and, as recently shown, surprising events. A general computational function of the STN appears to be to generate a pause. Under some circumstances, this could allow time for more evidence to accumulate to do the "right thing"; in the case of surprise, this putatively interrupts cognition, which could lead to forgetting recent information but also better encoding of new information. Notably, stopping and surprise have a broad suppressive effect on the skeletomotor system, which may relate to the putatively broad impact of the STN on basal ganglia output, although anatomical evidence is still weak.

Stopping recruits prefrontal areas, such as the right IFC and pre-SMA, whereas conflict recruits dmPFC (probably including the pre-SMA). It is thought that these prefrontal areas project to the STN via hyperdirect pathways, for which there is substantial anatomical and imaging evidence, although still scant functional evidence. Stopping (which is an outright form of "response inhibition") is associated with an increase in beta band oscillations in the STN, whereas conflict is associated with an increase in LFOs. Another way of seeing this dissociation is that conflict reflects a need for control (related to LFO) and stopping reflects the implementation of control (related to beta), which could also reflect a cognitive/motor split. We hypothesize that stopping and conflict are implemented by dissociable fronto-STN pathways: stopping engages right IFC and a more ventral part of the STN and involves activity in the beta band, whereas conflict engages preSMA and a more dorsal part of the STN, and LFO (Fig. 1). These putatively dissociable circuits and functions could be recruited in close temporal succession, perhaps even in the same trial: for example, a study of the Stroop showed increases in both STN LFO and beta power (Brittain et al., 2012) consistent with recruitment of both conflict (to slow responding) and response inhibition (to prevent the irrelevant response) systems.

Yet the idea of topographical separation of LFO and beta in the STN needs to be further substantiated. Studies of the distribution of the power and reactivity of such activities have not so far provided conclusive evidence, in part because of the relatively poor spatial resolution of LFPs recorded from DBS electrodes, given the small size of the STN (Rodriguez-Oroz et al., 2011; Alegre et al., 2012; Zavala et al., 2014). The question may also be raised why neurons in the STN need to receive different inputs according to their topography when the relevant information is already separated by carrier frequency. We suppose that an organization that uses both systems of keeping information streams separate (frequency band and anatomical location) might help ameliorate problems associated with reliance on just one system (i.e., limits of information coding capacity in the frequency domain and limits of integration across channels in the anatomical domain).

Studies of stopping and conflict show that there are firing rate changes in the STN; and for conflict at least, single-unit activity within the STN exhibits preferential firing during the peaks of theta and beta oscillations in the presence of conflict (Zavala et al., 2015b). This suggests that mPFC (and perhaps similarly inferior frontal gyrus) may therefore influence the timing of responses during action selection through synchronized oscillations with the basal ganglia that affect STN spiking activity.

Our theory of dissociable networks for stopping and conflict could be tested in several ways, including by developments with in vivo ultra-high resolution MRI that allows testing these more finegrained hypotheses about corticosubthalamic networks. When combined with postmortem histology and other data, this could help resolve functional subdivisions in the STN. Moreover, validating the idea of dissociable networks for stopping versus conflict could help to design more focused DBS approaches that optimize decision-making while minimizing side effects on speech and cognition.

\section{References}

Albin RL, Young AB, Penney JB (1989) The functional anatomy of basal ganglia disorders. Trends Neurosci 12:366-375. CrossRef Medline

Alegre M, Lopez-Azcarate J, Obeso I, Wilkinson L, Rodriguez-Oroz MC, Valencia M, Garcia-Garcia D, Guridi J, Artieda J, Jahanshahi M, Obeso JA (2012) The subthalamic nucleus is involved in successful inhibition in the stop-signal task: a local field potential study in Parkinson's disease. Exp Neurol 239:1-12.

Alkemade A (2013) Subdivisions and anatomical boundaries of the subthalamic nucleus. J Neurosci 33:9233-9234. CrossRef Medline

Alkemade A, Schnitzler A, Forstmann BU (2015) Topographic organization of the human and non-human primate subthalamic nucleus. Brain Struct Funct 220:3075-3086. CrossRef Medline

Aron AR, Poldrack RA (2006) Cortical and subcortical contributions to Stop signal response inhibition: role of the subthalamic nucleus. J Neurosci 26:2424-2433. CrossRef Medline

Aron AR, Behrens TE, Smith S, Frank MJ, Poldrack RA (2007) Triangulating a cognitive control network using diffusion-weighted magnetic resonance imaging (MRI) and functional MRI. J Neurosci 27:3743-3752. CrossRef Medline

Aron AR, Robbins TW, Poldrack RA (2014) Inhibition and the right inferior frontal cortex: one decade on. Trends Cogn Sci 18:177-185. CrossRef Medline

Badry R, Mima T, Aso T, Nakatsuka M, Abe M, Fathi D, Foly N, Nagiub H, Nagamine T, Fukuyama H (2009) Suppression of human corticomotoneuronal excitability during the Stop-signal task. Clin Neurophysiol 120:1717-1723. CrossRef Medline

Bari A, Robbins TW (2013) Inhibition and impulsivity: behavioral and neural basis of response control. Prog Neurobiol 108:44-79. CrossRef Medline

Bastin J, Polosan M, Benis D, Goetz L, Bhattacharjee M, Piallat B, Krainik A, Bougerol T, Chabardès S, David O (2014) Inhibitory control and error monitoring by human subthalamic neurons. Transl Psychiatry 4:e439. CrossRef Medline

Benis D, David O, Lachaux JP, Seigneuret E, Krack P, Fraix V, Chabardès S, Bastin J (2014) Subthalamic nucleus activity dissociates proactive and reactive inhibition in patients with Parkinson's disease. Neuroimage 91: 273-281. CrossRef Medline

Beudel M, Brown P (2016) Adaptive deep brain stimulation in Parkinson's disease. Parkinsonism Relat Disord 22 [Suppl 1]:S123-126. CrossRef Medline

Bogacz R, Gurney K (2007) The basal ganglia and cortex implement optimal decision making between alternative actions. Neural Comput 19:442477. CrossRef Medline

Brittain JS, Watkins KE, Joundi RA, Ray NJ, Holland P, Green AL, Aziz TZ, Jenkinson N (2012) A role for the subthalamic nucleus in response inhibition during conflict. J Neurosci 32:13396-13401. CrossRef Medline

Burbaud P, Clair AH, Langbour N, Fernandez-Vidal S, Goillandeau M, Michelet T, Bardinet E, Chéreau I, Durif F, Polosan M, Chabardès S, Fontaine D, Magnié-Mauro MN, Houeto JL, Bataille B, Millet B, Vérin M, Baup N, Krebs MO, Cornu P, et al. (2013) Neuronal activity correlated with checking behaviour in the subthalamic nucleus of patients with obsessive-compulsive disorder. Brain 136:304-317. CrossRef Medline

Buzsáki G, Anastassiou Ca, Koch C (2012) The origin of extracellular fields and currents: EEG, ECoG, LFP and spikes. Nat Rev Neurosci 13:407-420. CrossRef Medline

Cai W, George JS, Chambers CD, Stokes MG, Verbruggen F, Aron AR (2012) Stimulating deep cortical structures with the batwing coil: how to determine the intensity for transcranial magnetic stimulation using coil-cortex distance. J Neurosci Methods 204:238-241. CrossRef Medline

Cavanagh JF, Wiecki TV, Cohen MX, Figueroa CM, Samanta J, Sherman SJ, Frank MJ (2011) Subthalamic nucleus stimulation reverses me- 
diofrontal influence over decision threshold. Nat Neurosci 14:14621467. CrossRef Medline

Cavanagh JF, Figueroa CM, Cohen MX, Frank MJ (2012) Frontal theta reflects uncertainty and unexpectedness during exploration and exploitation. Cereb Cortex 22:2575-2586. CrossRef Medline

Chambers CD, Garavan H, Bellgrove MA (2009) Insights into the neural basis of response inhibition from cognitive and clinical neuroscience. Neurosci Biobehav Rev 33:631-646. CrossRef Medline

Chikazoe J (2010) Localizing performance of go/no-go tasks to prefrontal cortical subregions. Curr Opin Psychiatry 23:267-272. CrossRef Medline

Cohen MX, Cavanagh JF (2011) Single-trial regression elucidates the role of prefrontal theta oscillations in response conflict. Front Psychol 2:30.

Coxon JP, Stinear CM, Byblow WD (2007) Selective inhibition of movement. J Neurophysiol 97:2480-2489. CrossRef Medline

Coxon JP, Van Impe A, Wenderoth N, Swinnen SP (2012) Aging and inhibitory control of action: cortico-subthalamic connection strength predicts stopping performance. J Neurosci 32:8401-8412. CrossRef Medline

Cui G, Jun SB, Jin X, Pham MD, Vogel SS, Lovinger DM, Costa RM (2013) Concurrent activation of striatal direct and indirect pathways during action initiation. Nature 494:238-242. CrossRef Medline

de Hollander G, Keuken MC, Forstmann BU (2015) The subcortical cocktail problem: mixed signals from the subthalamic nucleus and substantia nigra. PLoS One 10:e0120572. CrossRef Medline

DeLong MR (1990) Primate models of movement disorders of basal ganglia origin. Trends Neurosci 13:281-285. Medline

Eagle DM, Baunez C, Hutcheson DM, Lehmann O, Shah AP, Robbins TW (2007) Stop-signal reaction-time task performance: role of prefrontal cortex and subthalamic nucleus. Cereb Cortex 18:178-188. CrossRef Medline

Fogelson N, Williams D, Tijssen M, van Bruggen G, Speelman H, Brown P (2006) Different functional loops between cerebral cortex and the subthalmic area in Parkinson's disease. Cereb Cortex 16:64-75. CrossRef Medline

Forstmann BU, Keuken MC, Jahfari S, Bazin PL, Neumann J, Schäfer A, Anwander A, Turner R (2012) Cortico-subthalamic white matter tract strength predicts interindividual efficacy in stopping a motor response. Neuroimage 60:370-375. CrossRef Medline

Frank MJ (2006) Hold your horses: a dynamic computational role for the subthalamic nucleus in decision making. Neural Netw 19:1120-1136. CrossRef Medline

Frank MJ, Gagne C, Nyhus E, Masters S, Wiecki TV, Cavanagh JF, Badre D (2015) fMRI and EEG predictors of dynamic decision parameters during human reinforcement learning. J Neurosci 35:485-494. CrossRef Medline

Fries P (2005) A mechanism for cognitive dynamics: neuronal communication through neuronal coherence. Trends Cogn Sci 9:474-480. CrossRef Medline

Fumagalli M, Giannicola G, Rosa M, Marceglia S, Lucchiari C, Mrakic-Sposta S, Servello D, Pacchetti C, Porta M, Sassi M, Zangaglia R, Franzini A, Albanese A, Romito L, Piacentini S, Zago S, Pravettoni G, Barbieri S, Priori A (2011) Conflict-dependent dynamic of subthalamic nucleus oscillations during moral decisions. Soc Neurosci 6:243-256. CrossRef Medline

Gillies AJ, Willshaw DJ (1998) A massively connected subthalamic nucleus leads to the generation of widespread pulses. Proc Biol Sci 265:2101-2109. CrossRef Medline

Goldberg JH, Farries MA, Fee MS (2013) Basal ganglia output to the thalamus: still a paradox. Trends Neurosci 36:695-705. CrossRef Medline

Greenhouse I, Oldenkamp CL, Aron AR (2012) Stopping a response has global or nonglobal effects on the motor system depending on preparation. J Neurophysiol 107:384-392. CrossRef Medline

Grill WM, Snyder AN, Miocinovic S (2004) Deep brain stimulation creates an informational lesion of the stimulated nucleus. Neuroreport 15:11371140. CrossRef Medline

Haber S (2003) The primate basal ganglia: parallel and integrative networks. J Chem Neuroanat 26:317-330. CrossRef Medline

Hanks T, Kiani R, Shadlen MN (2014) A neural mechanism of speedaccuracy tradeoff in macaque area LIP. Elife 3. CrossRef Medline

Haynes WI, Haber SN (2013) The organization of prefrontal-subthalamic inputs in primates provides an anatomical substrate for both functional specificity and integration: implications for Basal Ganglia models and deep brain stimulation. J Neurosci 33:4804-4814. CrossRef Medline

Hershey T, Revilla F, Wernle A, Gibson P (2004) Stimulation of STN im- pairs aspects of cognitive control in PD. Neurology 62:1110-1114. CrossRef

Herz DM, Christensen MS, Bruggemann N, Hulme OJ, Ridderinkhof KR, Madsen KH, Siebner HR (2014) Motivational tuning of frontosubthalamic connectivity facilitates control of action impulses. J Neurosci 34:3210-3217. CrossRef Medline

Herz DM, Zavala BA, Bogacz R, Brown P (2016) Neural correlates of decision thresholds in the human subthalamic nucleus. Curr Biol 26:916-920. CrossRef Medline

Inase M, Tokuno H, Nambu A, Akazawa T, Takada M (1999) Corticostriatal and corticosubthalamic input zones from the presupplementary motor area in the macaque monkey: comparison with the input zones from the supplementary motor area. Brain Res 833:191-201. CrossRef Medline

Isoda M, Hikosaka O (2008) Role for subthalamic nucleus neurons in switching from automatic to controlled eye movement. J Neurosci 7209 7218. CrossRef Medline

Jahanshahi M, Obeso I, Rothwell JC, Obeso JA (2015) A fronto-striatosubthalamic-pallidal network for goal-directed and habitual inhibition. Nat Rev Neurosci 16:719-732. CrossRef Medline

Keuken MC, Forstmann BU (2015) A probabilistic atlas of the basal ganglia using 7 T MRI. Data Brief 4:577-582. CrossRef Medline

King AV, Linke J, Gass A, Hennerici MG, Tost H, Poupon C, Wessa M (2012) Microstructure of a three-way anatomical network predicts individual differences in response inhibition: a tractography study. Neuroimage 59: 1949-1959. CrossRef Medline

Kravitz AV, Tye LD, Kreitzer AC (2012) Distinct roles for direct and indirect pathway striatal neurons in reinforcement. Nat Neurosci 15:816-818. CrossRef Medline

Kühn AA, Volkmann J (2016) Innovations in deep brain stimulation methodology. Mov Disord. Advance online publication. Retrieved Jul 12, 2016. doi: $10.1002 / \mathrm{mds} .26703$. CrossRef Medline

Kühn AA, Williams D, Kupsch A, Limousin P, Hariz M, Schneider GH, Yarrow K, Brown P (2004) Event-related beta desynchronization in human subthalamic nucleus correlates with motor performance. Brain 127: 735-746. CrossRef Medline

Leventhal DK, Gage GJ, Schmidt R, Pettibone JR, Case AC, Berke JD (2012) Basal ganglia beta oscillations accompany cue utilization. Neuron 73:523536. CrossRef Medline

Li CS, Yan P, Sinha R, Lee TW (2008) Subcortical processes of motor response inhibition during a stop signal task. Neuroimage 41:1352-1363. CrossRef Medline

Lisman JE, Jensen O (2013) The $\theta-\gamma$ neural code. Neuron 77:1002-1016. CrossRef Medline

MacDonald HJ, Coxon JP, Stinear CM, Byblow WD (2014) The fall and rise of corticomotor excitability with cancellation and reinitiation of prepared action. J Neurophysiol 112:2707-2717. CrossRef Medline

Magill PJ, Sharott A, Bevan MD, Brown P, Bolam JP (2004) Synchronous unit activity and local field potentials evoked in the subthalamic nucleus by cortical stimulation. J Neurophysiol 92:700-714. CrossRef Medline

Majid DS, Cai W, George JS, Verbruggen F, Aron AR (2012) Transcranial magnetic stimulation reveals dissociable mechanisms for global versus selective corticomotor suppression underlying the stopping of action. Cereb Cortex 22:363-371. CrossRef Medline

Mansfield EL, Karayanidis F, Jamadar S, Heathcote A, Forstmann BU (2011) Adjustments of response threshold during task switching: a model-based functional magnetic resonance imaging study. J Neurosci 31:1468814692. CrossRef Medline

McHaffie JG, Stanford TR, Stein BE, Coizet V, Redgrave P (2005) Subcortical loops through the basal ganglia. Trends Neurosci 28:401-407. CrossRef Medline

Mink JW (1996) The basal ganglia: focused selection and inhibition of competing motor programs. Prog Neurobiol 50:381-425. CrossRef Medline

Nambu A, Tokuno H, Inase M, Takada M (1997) Corticosubthalamic input zones from forelimb representations of the dorsal and ventral divisions of the premotor cortex in the macaque monkey: comparison with the input zones from the primary motor cortex and the supplementary motor area. Neurosci Lett 239:13-16. CrossRef Medline

Nambu A, Tokuno H, Takada M (2002) Functional significance of the cortico-subthalamo-pallidal 'hyperdirect' pathway. Neurosci Res 43: 111-117. CrossRef Medline

Nambu A, Tachibana Y, Chiken S (2015) Cause of parkinsonian symptoms: 
firing rate, firing pattern or dynamic activity changes? Basal Ganglia $5: 1-6$.

Obeso I, Wilkinson L, Casabona E, Speekenbrink M, Luisa Bringas M, Álvarez M, Álvarez L, Pavón N, Rodríguez-Oroz MC, Macías R, Obeso JA, Jahanshahi M (2014) The subthalamic nucleus and inhibitory control: impact of subthalamotomy in Parkinson's disease. Brain 137: 1470-1480. CrossRef Medline

Parent A, Hazrati LN (1995) Functional anatomy of the basal ganglia: I. The cortico-basal ganglia-thalamo-cortical loop. Brain Res Brain Res Rev 20: 91-127. CrossRef Medline

Parsons TD, Rogers SA, Braaten AJ, Woods SP, Tröster AI (2006) Cognitive sequelae of subthalamic nucleus deep brain stimulation in Parkinson's disease: a meta-analysis. Lancet Neurol 5:578-588. CrossRef Medline

Rae CL, Hughes LE, Anderson MC, Rowe JB (2015) The prefrontal cortex achieves inhibitory control by facilitating subcortical motor pathway connectivity. J Neurosci 35:786-794. CrossRef Medline

Ray NJ, Brittain JS, Holland P, Joundi RA, Stein JF, Aziz TZ, Jenkinson N (2012) The role of the subthalamic nucleus in response inhibition: evidence from local field potential recordings in the human subthalamic nucleus. Neuroimage 60:271-278. CrossRef Medline

Ridderinkhof KR, Ullsperger M, Crone EA, Nieuwenhuis S (2004) The role of the medial frontal cortex in cognitive control. Science 306:443-447. CrossRef Medline

Ridderinkhof KR, Forstmann BU, Wylie SA, Burle B, van den Wildenberg WP (2011) Neurocognitive mechanisms of action control: resisting the call of the Sirens. Wiley Interdiscip Rev Cogn Sci 2:174-192. CrossRef Medline

Rodriguez-Oroz MC, López-Azcárate J, Garcia-Garcia D, Alegre M, Toledo J, Valencia M, Guridi J, Artieda J, Obeso JA (2011) Involvement of the subthalamic nucleus in impulse control disorders associated with Parkinson's disease. Brain 134:36-49. CrossRef Medline

Rutishauser U, Ross IB, Mamelak AN, Schuman EM (2010) Human memory strength is predicted by theta-frequency phase-locking of single neurons. Nature 464:903-907. CrossRef Medline

Schall JD, Godlove DC (2012) Current advances and pressing problems in studies of stopping. Curr Opin Neurobiol 22:1012-1021. CrossRef Medline

Schmidt R, Leventhal DK, Mallet N, Chen F, Berke JD (2013) Canceling actions involves a race between basal ganglia pathways. Nat Neurosci 16:1118-1124. CrossRef Medline

Sejnowski TJ, Paulsen O (2006) Network oscillations: emerging computational principles. J Neurosci 26:1673-1676. CrossRef Medline

Swann NC, Cai W, Conner CR, Pieters TA, Claffey MP, George JS, Aron AR, Tandon N (2012) Roles for the pre-supplementary motor area and the right inferior frontal gyrus in stopping action: electrophysiological responses and functional and structural connectivity. Neuroimage 59: 2860-2870. CrossRef Medline

Swann N, Tandon N, Canolty R, Ellmore TM, McEvoy LK, Dreyer S, DiSano M, Aron AR (2009) Intracranial EEG reveals a time- and frequencyspecific role for the right inferior frontal gyrus and primary motor cortex in stopping initiated responses. J Neurosci 29:12675-12685. CrossRef Medline

Taylor PC, Nobre AC, Rushworth MF (2007) Subsecond changes in top down control exerted by human medial frontal cortex during conflict and action selection: a combined transcranial magnetic stimulation electroencephalography study. J Neurosci 27:11343-11353. CrossRef Medline

Temel Y, Blokland A, Steinbusch HW, Visser-Vandewalle V (2005) The functional role of the subthalamic nucleus in cognitive and limbic circuits. Prog Neurobiol 76:393-413. CrossRef Medline

Thura D, Cisek P (2016) Modulation of premotor and primary motor cortical activity during volitional adjustments of speed-accuracy trade-offs. J Neurosci 36:938-956. CrossRef Medline

Verbruggen F, Logan GD (2008) Response inhibition in the stop-signal paradigm. Trends Cogn Sci 12:418-424. CrossRef Medline
Watanabe T, Hanajima R, Shirota Y, Tsutsumi R, Shimizu T, Hayashi T, Terao Y, Ugawa Y, Katsura M, Kunimatsu A, Ohtomo K, Hirose S, Miyashita Y, Konishi S (2015) Effects of rTMS of pre-supplementary motor area on fronto basal ganglia network activity during stop-signal task. J Neurosci 35:4813-4823. CrossRef Medline

Weintraub DB, Zaghloul KA (2013) The role of the subthalamic nucleus in cognition. Rev Neurosci 24:125-138. CrossRef Medline

Wessel JR, Aron AR (2013) Unexpected events induce motor slowing via a brain mechanism for action-stopping with global suppressive effects. J Neurosci 33:18481-18491. CrossRef Medline

Wessel JR, Reynoso HS, Aron AR (2013a) Saccade suppression exerts global effects on the motor system. J Neurophysiol 110:883-890. CrossRef Medline

Wessel JR, Conner CR, Aron AR, Tandon N (2013b) Chronometric electrical stimulation of right inferior frontal cortex increases motor braking. J Neurosci 33:19611-19619. CrossRef Medline

Wessel JR, Jenkinson N, Brittain JS, Voets SH, Aziz TZ, Aron AR (2016a) Surprise disrupts cognition via a fronto-basal ganglia suppressive mechanism. Nat Commun 7:11195. CrossRef Medline

Wessel J, Ghahremani A, Udupa K, Saha U, Kalia SK, Hodaie M, Lozano AM, Aron A, Chen R (2016b) Stop-related subthalamic beta activity indexes global motor suppression in Parkinson's Disease. Mov Disord. Advance online publication. Retrieved Jul 30, 2016. doi: 10.1002/mds.26732. CrossRef Medline

Wiecki TV, Frank MJ (2013) A computational model of inhibitory control in frontal cortex and basal ganglia. Psychol Rev 120:329-355. CrossRef Medline

Wilson CJ, Beverlin B 2nd, Netoff T (2011) Chaotic desynchronization as the therapeutic mechanism of deep brain stimulation. Front Syst Neurosci 5:50. CrossRef Medline

Xu B, Sandrini M, Wang WT, Smith JF, Sarlls JE, Awosika O, Butman JA, Horwitz B, Cohen LG (2016) PreSMA stimulation changes task-free functional connectivity in the fronto-basal-ganglia that correlates with response inhibition efficiency. Hum Brain Mapp 37:3236-3239. CrossRef Medline

Zaghloul KA, Weidemann CT, Lega BC, Jaggi JL, Baltuch GH, Kahana MJ (2012) Neuronal activity in the human subthalamic nucleus encodes decision conflict during action selection. J Neurosci 32:2453-2460. CrossRef Medline

Zandbelt BB, Vink M (2010) On the role of the striatum in response inhibition. PLoS One 5:e13848. CrossRef Medline

Zandbelt BB, Bloemendaal M, Hoogendam JM, Kahn RS, Vink M (2013) Transcranial magnetic stimulation and functional MRI reveal cortical and subcortical interactions during stop-signal response inhibition. J Cogn Neurosci 25:157-174. CrossRef Medline

Zavala BA, Tan H, Little S, Ashkan K, Hariz M, Foltynie T, Zrinzo L, Zaghloul KA, Brown P (2014) Midline frontal cortex low-frequency activity drives subthalamic nucleus oscillations during conflict. J Neurosci 34: 7322-7333. CrossRef Medline

Zavala B, Brittain JS, Jenkinson N, Ashkan K, Foltynie T, Limousin P, Zrinzo L, Green AL, Aziz T, Zaghloul K, Brown P (2013) Subthalamic nucleus local field potential activity during the Eriksen flanker task reveals a novel role for theta phase during conflict monitoring. J Neurosci 33:1475814766. CrossRef Medline

Zavala B, Zaghloul K, Brown P (2015a) The subthalamic nucleus, oscillations, and conflict. Mov Disord 30:328-338. CrossRef Medline

Zavala B, Damera S, Dong JW, Lungu C, Brown P, Zaghloul KA (2015b) Human subthalamic nucleus theta and beta oscillations entrain neuronal firing during sensorimotor conflict. Cereb Cortex. Advance online publication. Retrieved Oct 22, 2015. doi: 10.1093/cercor/bhv244. CrossRef Medline 